\title{
Alexander Drews
}

\section{Semantik und Ethik des Wortfeldes »Ergon« im Johannesevangelium}

\author{
Kontexte und Normen neutestamentlicher Ethik / Contexts and Norms of New
} Testament Ethics. Band VIII

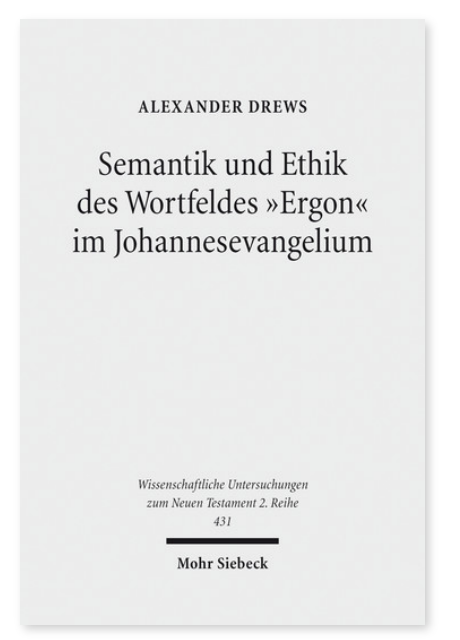

2017. XIX, 324 Seiten. WUNT II 431

ISBN 978-3-16-154912-0

DOI 10.1628/978-3-16-154912-0

eBook PDF 104,00€

ISBN 978-3-16-154660-0

fadengeheftete Broschur 104,00€
In dieser Studie stellt Alexander Drews den Gebrauch, die Semantik und die moralische Signifikanz des Wortfeldes Ergon im Johannesevangelium heraus. Dabei diskutiert er alle relevanten Belegstellen und vergleicht ihre Bedeutung mit dem berühmten Ergon -Argument von Aristoteles und einem antiken Textkorpus. Das Herzstück der Arbeit ist ein ausführlicher exegetischer Teil, in dem das Wortfeld auf seine ethische Wirkung hin ausgewertet wird. Als zentral wird hier der Abschnitt in Joh 3,18-21 gesehen, der eine Perspektive vom 'Raum des Lichts', vom 'Raum der Dunkelheit' und einem 'ambivalenten Handlungsraum' eröffnet und damit dem Leser Handlungsimpulse bietet. Methodisch beschreitet der Autor Neuland, indem er in Bezug auf die Semantik die Korpuslinguistik erprobt und in Bezug auf die Ethik die Methodologie zur 'impliziten Ethik' von Ruben Zimmermann anwendet.

Alexander Drews Geboren 1976; 1999-2005 Studium der Ev. Theologie; 2005-16 u.a. Berufsberater; seit 2014 zugleich Leiter der Schulsozialarbeit, August-Hermann-Francke-Schulen in Lippe (Detmold); 2015 nebenberufl. Promotion in Ev. Theologie, Universität Siegen; seit 2016 u. a. Lehrer im Feststellungsverfahren für Ev. Religion am AHF-Gymnasium (Detmold).
Jetzt bestellen:
https://mohrsiebeck.com/buch/semantik-und-ethik-des-wortfeldes-ergon-im-johannesevangelium-9783161549120?
no_cache=1
order@mohrsiebeck.com
Telefon: +49 (0)7071-923-17
Telefax: +49(0)7071-51104 